\title{
Epidemiological Study Of The Childhood Disabilities: A Household Survey In Four Egyptian Governorates
}

\author{
E. A. El-Moselhy; R. M. El-Azab; H. O. Khalifa; E. S. Abd-Allah*; \\ A. M. Ebrahim **; H. M. El-Masry***; T. S. El-Shorbgy****and \\ H. S. Abo Seif***** \\ Departments of Community and Industrial Medicine; Community Health Nursing*; Paychiatry \\ **; Paediatrics***; ENT ${ }^{* * * * *}$ and Ophthalmology***** \\ Faculty of Medicine and Nursing, Al-Azhar and Zagazig University
}

\begin{abstract}
This study was conducted on 1403 children from four Egyptian governorates. These governorates were; Alexandria, Al-Behira, Cairo and Al-Giza. The aim of the study was to define different types of the childhood disabilities, to find out their prevalence's in the selected governorates in Egypt, to define their distribution and to define their risk factors. A crosssectional study design was chosen to investigate the current research problem. All the children had undergone complete physical examinations. Also, children's parents were interviewed. There were specific inclusions criteria have been considered to include the child as a case in the study. The overall prevalence of the childhood disabilities in these governorates was $8.8 \%$. The most common prevalent childhood disabilities were; visual, speech and hearing $(4.5 \%, 2.1 \%$ and $1.9 \%$, respectively). While, the most common prevalent risk factors were mother delivered at home and/or not received antenatal care $(7.2 \%$ and $6.3 \%$, respectively). Positive consanguinity and baby not strictly received vaccination were the most important risk factors, odds ratio $=3.81$ and 3.31 , respectively. While, only positive consanguinity was significantly correlated with all types of the childhood disabilities. Furthermore, positive consanguinity had the highest correlation with all types of the childhood disabilities. Also, childhood disabilities tend to be common among males $(57.6 \%)$ and of congenital aetiology $(61.8 \%)$. The main source of habilitation was the private centers $(79.2 \%)$.
\end{abstract}

\section{Introduction}

With a dramatic decrease in infant mortality, a challenge facing modern medicine is chronic disabling conditions in infants and young children (Chen and Simeonsson, 1993). Childhood disability is a major health problem that is pronounced in developing countries (Shawky et al., 2002). Disability according to estimates of the United Nations affect lives of more than 600 million people globally. This means that about $10.0 \%$ of the world's population is disabled. Looking only at developing countries, the numbers are expected to be much higher. Difficult conceptual issues as well as social and cultural differences have inhibited the collection of the data needed to properly estimate the prevalence of disability in the world especially in developing countries. International efforts are now underway to improve the quality and availability of data about disability (WHO, 2004).

In Egypt, prevalence of childhood disability was estimated to be about $8.0 \%$, 


\section{E. A. El-Moselhy et al}

i.e., there are about 2.5 million children aged less than 18 with one or more physical or mental disabilities. During nineties 28.000 children were enrolled in special education classes, but this represent only about 5.0\% of them (UNDP, 2004).

The WHO has developed the international classification of disability and handicaps (ICDH) since 1980. Disability was defined as any restriction or lack of ability (resulting from an impairment) to perform an activity in the manner or within the range considered normal for a human being. Impairment was defined as any loss or abnormality of psychological, physiological, or anatomical structure or function. While, handicap, resulting from an impairment or disability, was defined as that limits or prevents the fulfillments of a role that is normal (depending on age, sex, soc-ial and cultural factors) for that individual (WHO, 1980).

Research on factors contributing to disability indicates the complexity of the problem. Disability may result from congenital or acquired causes and it may be obvious at birth or may appear later in life. The causative factors leading to disability are heterogeneous and complex and their contribution in producing disability may differ in different populations. Furthermore, the aetiolgy of a substantial percentage of disability remains unknown (Gortmaker \& Sappenfield, 1984; Chen \& Simeonsson, 1993 and El-Hazmi, 1997). The aetiological factors in the development of disability may be present at preconception, prenatal, natal and postnatal period. As disability is chronic in nature, its early detection, early care and management may arrest the disability process or ameliorate the complications resulting from the disabling process. The detection or diagnosis takes into consideration the aetiological factors and separate protocols are followed depending on whether the disability is congenital or acquired (Roubertie et al., 2004). Efforts to prevent developmental disabilities among children can be classified in terms of primary, secondary and tertiary activities
(Chen \& Simeonsson, 1993 and El-Hazmi, 1997).

This study will spot the light on the prevalence, distribution and nature of the different disabilities among children. Identification of disabilities is considered as a basic need for primary prevention of disability among children.

\section{Study Objectives: \\ General Objective:}

- To prevent and control childhood disabilities in Egypt.

\section{Specific Objectives:}

- To define different types of childhood disabilities and to find out their prevalence's in the selected governorates in Egypt.

- To define distribution of different types of the childhood disabilities.

- To define risk factors of different types of the childhood disabilities.

\section{Subjects And Methods}

Research Setting: This study was conducted in four governorates of Egypt: Alexandria (east district), Al-Behira (some Damnhour's villages; Desos om dinar, AlAbaadia and Nediba), Cairo (east district; Al-Matrya and Al-Mrg and south district; Ezzbet Khayrallah and Albasateen) and AlGiza (Manial Sheha, Tamouh, Zawyet Abo musllam, Nazlet Alashtar and Kaseb villages).These governorates and areas were chosen purposively as there were facilities in examining the studied children and interviewing their parents (N.B. PLAN International Organization, a non-governmental organization is working with these families in the previously mentioned areas).

Research Design: A cross-sectional analytical research design was chosen to investigate the current research problem. A pilot study was carried out on 130 children during the first three months to help in the finalization of the research instruments and forms as well as the finalization of the study design. It was guided by the following tasks:

i. Testing the form design, content and language at the study sites. 
ii. Measuring the time and resources needed for the fieldwork.

Sample Design: Equation for sample size was applied and calculated based on the following data; prevalence of the childhood disabilities in Egypt (about 8.0\%) according to the report of UNDP (2004) and margin of sampling error tolerated (2.0\%). So, the resulted sample was 708 and to avoid sample size bias the total sample was increased to reach 1403 children. The selection of children from each governorate was done by simple random sampling technique to be as follows: Alexandria (287), Al-Behira (148), Cairo (695) and AlGiza (273). The following inclusion criteria have been considered during selection of the studied children:

i. Age up to 18 years.

ii. Only from the previously mentioned areas and families.

All children had undergone complete physical examinations. Children's parents, also, were submitted to an interview.

Diagnosis of childhood disabilities: The following diagnostic criteria have been considered a basic prerequisite to include the child as a case in the study:

1. Visual disability:

i. Previously diagnosed as a case of visual disability (blind, with aided acuity of vision $<1 / 60$ or weak sight, with aided acuity of vision $<6 / 18$ ).

ii. Discovered to be as a case of visual disability during our examination by the visual acuity chart (broken $\mathrm{C}$, letter or illiterate) or by the colored rotating drum for preferential looking for babies.

\section{Hearing disability:}

i. Previously diagnosed as a case of hearing disability (deaf or hearing impaired).

ii. Discovered to be as a case of hearing disability during our examination by a portable audiometer (Bosch Telecom). Degree of hearing loss was made according to Gelfand (2004) scale:

\begin{tabular}{|l|l|}
\hline \multicolumn{1}{|c|}{ Degree of hearing loss } & \multicolumn{1}{c|}{ dB range } \\
\hline Mild/moderate loss & $>20-55 \mathrm{~dB}$ \\
\hline Severe/profound loss & $>55->90 \mathrm{~dB}$ \\
\hline
\end{tabular}

3. Speech disability:

i. Previously diagnosed as a case of speech disability (stammer, stutter ...etc.).

ii. Discovered to be as a case of speech disability during our examination.

4. Motor disability:

i. Previously diagnosed as a case of motor disability (upper and/or lower motor neuron lesion).

ii. Discovered to be as a case of motor disability during our examination.

5. Mental disability:

i. Previously diagnosed as a case of mental disability (mental etardation, autism, epilepsy ....etc.)

ii. Discovered to be as a case of mental disability during our examination.

6. Multiple disabilities:

i. Previously diagnosed as a case of multiple disabilities (have one or more of the previously mentioned disabilities or as in cerebral palsy $(\mathrm{CP})$ and other associated syndroms)

ii. Discovered to be as a case of multiple disabilities during our examination.

Data Collection and Statistical Analysis: In coordination with PLAN, we visited the homes to run the study. The parents of the children were briefed on the objectives of the study and how it will be administered. A verbal consent from the children's parents to participate in the study was taken. Other ethical issues were considered. The collected data were statistically managed. The chi-square $\left(\chi^{2}\right)$, odds ratio (OR) with $95 \%$ confidence interval (CI) or exact confidence limits (ECL), correlation coefficient (r) and stepwise regression analysis were used as tests of significance. The significance level for $\chi^{2}$ and $r$ and were accepted if the $\mathrm{P}$-value $\leq 0.05$.

\section{Results And Discussion}

This study, (table 1) demonstrated the prevalence of the childhood disabilities and their risk factors in different studied locations. It was clear that $124(8.8 \%)$ of the 


\section{E. A. El-Moselhy et al}

studied children had different types of disabilities. Andersen et al. (1990) cleared that at age four, $1.1 \%$ of children had disabilities. Chen and Simeonsson (1993) stated that the overall prevalence of childhood disabilities was $2.7 \%$ among Chine's children. Janson and Dawani (1994) found that $7.8 \%$ of children had a disability or a chronic disease. Ansari and Akhadar (1998) showed $4.7 \%$ prevalence of impairments in Saudi Arabian children less than 15 years. MOLISA (1998) reported that prevalence of childhood disability was $3.1 \%$ among children aged 0-17 years old, in Vietnam. While, in Egypt, prevalence of childhood disabilities was estimated to be about $8.0 \%$ among children aged less than 18 (UNDP, 2004). The lowest figure (1.1\%) can be explained, small age of the children and developed country, Denmark. In this study, the highest percentages of disabilities were found in Alexandria and Cairo, 9.4\% for both. At the same time, the total number of disabilities in all studied areas was 144 $(10.3 \%)$. Again, the highest percentages were found in Alexandria (12.9\%) and Cairo $(10.1 \%)$. As regard visual disability, there were $63(4.5 \%)$ children. MOLISA (1998) found, $0.61 \%$ prevalence of visual disability. Khandekar and Abdu-Helmi (2004) reported, $4.1 \%$ prevalence of myopia in Oman school children. While, the prevalence of ambiopia was $0.3 \%$. Also, Nasir et al. (2004) cleared that $2.0 \%$ of the children in Afghanistan were visually handicapped. In this study, the highest percentages of visual disability were found in Cairo (6.2\%) and Alexandria (3.5\%). Khandekar and Abdu-Helmi (2004) stated that regional variation in myopic trend was marked. Regarding hearing disability, there were 27 (1.9\%) children. MOLISA (1998) found, $0.4 \%$ prevalence of hearing disability. Again, Nasir et al. (2004) cleared that $9.0 \%$ of children had hearing impairment. Our result comes between the previously mentioned figures. The highest figure $(9.0 \%)$ could be explained, underdeveloped country, Afghanistan. At the same time, the highest percentages of hearing disability were found in Cairo
(2.2\%) and Alexandria (2.1\%). As regard speech disability, there were $30(2.1 \%)$ children. MOLISA (1998) found, 0.89\% prevalence of speech disability. Broomfield and Dodd (2004) clarified that prevalence of children who had speech and language disability was $14.6 \%$. This higher figure could be explained, co-morbid speech and language defects. The highest percentage of speech disability was found in Alexandria (4.2\%). While, motor disability was found among $9(0.6 \%)$ children. Roubertie et al. (2004) showed that movement disorders are not uncommon in childhood. Andersen et al. (1990) cleared that $5.1 \%$ of children had motor handicap. MOLISA (1998) found, $0.93 \%$ prevalence of motor disability. Nasir et al. (2004) found that $25.0 \%$ of children had delayed physical and mental development. In this study, the highest percentage of motor disability was found in Al-Giza (1.1\%). Regarding mental disability, there were $15(1.1 \%)$ children. Andersen et al. (1990) clarified that $7.0 \%$ of children had mental retardation. Chen and Simeonsson (1993) cleared that for children less than 14 years of age in China; the prevalence of mental retardation was $1.8 \%$. Nasir et al. (2004) reported that $13.0 \%$ of children had CP and $52.0 \%$ of them had CP and mental retardation. Marlow et al. (2005) showed that cognitive impairment was present in $21.0 \%$ of the children born extremely preterm, this value rose to $41.0 \%$ when the results were compared with those for their classmates. This study (table 1), revealed that the highest percentage of mental disability was found in Alexandria (2.4\%). Lastly, multiple disabilities were found among $20(1.4 \%)$ children. MOLISA (1998) found that the average number of disabilities in child with disabilities was 1.2. In this study, the highest percentage of multiple disabilities was found in Alexandria (3.5\%). Nasir et al. (2004) cleared that regional variation in disabilities was obvious. At the same time, 60 (4.3\%) of the studied children their parents had a positive consanguinity history. Nasir et al. (2004) showed that $46.0 \%$ of the disabled children were born from parents who are first cousin. 
Abu-Rabia and Maroun (2005) stated that results indicated that the rate of disabilities among children of first cousin parents was higher than that of with children of second cousin parents, distantly related parents, or unrelated parents. It has been suggested that results provide new evidence for a genetic basis to disabilities. In this study, the highest percentages of positive consanguinity were found in Al-Behira (7.4\%) and Alexandria (5.6\%). Also, $89(6.3 \%)$ of the studied children their mothers did not receive antenatal care. Again, Nasir et al. (2004) showed that $58.3 \%$ of the disabled children were born from parents who lack antenatal care. Also, the highest percentages were found in Al-Behira (8.8\%) and Alexandria $(6.6 \%)$. While, 101 (7.2\%) of the studied children their mothers delivered them at home. Again, the highest percentages were found in Al-Behira (8.8\%) and Alexandria $(7.3 \%)$. Lastly, $25(1.8 \%)$ of the studied children did not strictly receive vaccination. Smith et al. (2005) stated that the incidence of acquired sensorineural hearing loss (SNHL) in children has fallen as a result of the widespread implementation of immunization programmes. The highest percentages of children who did not strictly received vaccination were found in Al-Behira $(2.0 \%)$ and Cairo (1.9\%).

As regard distribution of the disabled children in different studied locations according to type of disability (table 2), 63 $(50.8 \%)$ of them had visual disability. The highest percentages were found in Alexandria (37.0\%) and Cairo (66.2\%). Regarding hearing disability, there were 27 $(21.8 \%)$ children. Hutchison and Gordon (2005) reported a close figure, $18.0 \%$. The highest percentages were found in Al-Behira and Cairo, $23.1 \%$ for both. While, speech disability was found among 30 (24.2\%) children. Samuel et al. (1995) found speech disorders among 38.0\% of their group of disabled children. Also, MOLISA (1998) found that prevalence of speech disability was $21.4 \%$. While, Hutchison and Gordon (2005) reported a lower figure $14.0 \%$ the highest percentage was found in Alexandria (44.4\%). Regarding motor disability, there were $9(7.3 \%)$ children. Hutchison and Gordon (2005) reported a close figure (8.0\%). On the other hand, Samuel et al. (1995) and MOLISA (1998) reported higher figures, $16.0 \%$ and $22.4 \%$ of their group of disabled children, respectively. The highest percentage was found in Al-Giza (15.8\%). As regard mental disability, there were 15 (12.1\%) children. Chen and Simeonsson (1993) clarified that mental retardation was accounts for $66.0 \%$ of all disabled children, the most frequent childhood disability. Samuel et al. (1995) found global developmental delay among $20.0 \%$ of their group of disabled children. The highest percentage was found in Alexandria (25.9\%). Lastly, multiple disabilities were found among $20(16.1 \%)$ children. The highest percentage was found in Alexandria $(37.0 \%)$. At the same time, $60(48.4 \%)$ of the studied children their parents had a positive history of consanguinity. Janson \& Dawani (1994) and Durkin (2002) stated that consanguinity was an important risk factor for childhood disabilities. The highest percentages were found in Al-Behira $(84.6 \%)$ and Alexandria (59.3\%). Also, 89 $(71.8 \%)$ of the studied children their mothers did not receive antenatal care. The highest percentages were found in Al-Behira $(100.0 \%)$ and Al-Giza (73.7\%). While, 101 $(81.5 \%)$ of the studied children their mothers delivered them at home. The highest percentages were found in Al-Behira and Al-Giza, $100.0 \%$ for both. Lastly, 25 $(20.2 \%)$ of the studied children did not strictly receive vaccination. The highest percentages were found in Al-Giza (26.3\%) and Al-Behira (23.1\%).

As regard distribution of the disabled and non-disabled children according to presence of some risk factors among them (table 3), $48.4 \%$ and $20.0 \%$ of the disabled and non-disabled, respectively had a positive history of consanguinity $(\mathrm{OR}=3.75,95 \% \mathrm{CI}$ : 2.52-5.56). Abu-Rabia and Maroun (2005) stated that results provide new evidence for a genetic basis to disability. While, $71.8 \%$ and $54.7 \%$ of mothers of the disabled and non-disabled, respectively not received antenatal care $(\mathrm{OR}=2.11,95 \%$ CI: 1.38 - 


\section{E. A. El-Moselhy et al}

3.23). Larsson. et al. (2005) showed that there was no significant association between risk of autism and number of antenatal visits. Also, $81.5 \%$ and $62.6 \%$ of mothers of the disabled and non-disabled. respectively delivered them at home $(\mathrm{OR}=2.62,95 \% \mathrm{CI}$ : 1.61-4.30). Lastly, $20.2 \%$ and $5.6 \%$ of the disabled and non-disabled, respectively not strictly received their vaccination $(\mathrm{OR}=4.30$, 95\% CI: 2.53-7.27). Smith et al. (2005) supported our result.

Regarding distribution of the disabled and non-disabled children in different studied locations according to presence of some risk factors among them (table 4), $14.8 \%$ and $0.8 \%$ of the disabled and nondisabled, respectively in Alexandria not strictly received their vaccination $(\mathrm{OR}=22.43$, 95\% ECL: 2.96-253.76). Also, $84.6 \%$ and $16.3 \%$ of the disabled and nondisabled groups, respectively in Al-Behira had a positive history of consanguinity $(\mathrm{OR}=28.25$, 95\% ECL: 5.43-270.34). While, $20.0 \%$ and $4.0 \%$ of the disabled and nondisabled, respectively in Cairo not strictly received their vaccination $(\mathrm{OR}=6.05,95 \%$ CI: $2.74-13.22)$. Lastly, $52.6 \%$ and $20.1 \%$ of the disabled and non-disabled, respectively in Al-Giza had a positive history of consanguinity $\quad(\mathrm{OR}=4.42$, 95\% CI: 1.5612.62).

As regard correlation coefficient between risk factors and occurrence of different disabilities among the disabled children (table 5), a positive history of consanguinity was the only significant risk factor $(\mathrm{P}=0.00)$ regarding occurrence of visual disability. Al-Salem and Rawashdeh (1992) supported our result and stated that parental consanguinity in those with genetically determined causes of visual impairment was high compared with those with nongenetic causes (79\% vs. 33.3\%, $\mathrm{P}<0.05)$. Tabbara et al. (2005) showed that the incidence of consanguinity among parents of children with acquired causes of visual disability was $3.0 \%$ compared to $38.0 \%$ among genetically determined causes $(\mathrm{P}<0.001)$. While, a positive history of consanguinity and the mother not received antenatal care were the only significant risk factors $(\mathrm{P}=0.02$ and 0.03 , respectively) regarding occurrence of hearing disability. Shawky et al. (2002) showed that a consanguineous marriage was shown to put the mother at higher risk of having an auditory disabled child. Feinmesser et al. (1989) cleared that the rate of consanguinity among the parents of hearing-impaired children was much lower in their survey than in the earlier one. They assumed that there is a better understanding of the genetic risk in consanguineous unions, especially when a disability such as hereditary deafness is involved. Ganga et al. (1991) demonstrated that consanguinity was observed in $65.4 \%$ parents of deaf children, $23.1 \%$ had one or more affected sibling and $14.1 \%$ had affected relatives. Smith et al. (2005) mentioned that during the past decades the incidence of acquired SNHL in children living in more developed countries has fallen. The overall decrease has been accompanied by a relative increase in the proportion of inherited forms of SNHL. These changes in the incidence of SNHL have not been seen in children living in less developed countries, where the prevalence of consanguinity is high in many areas and both genetic and acquired forms of SNHL are common, particularly among children who live in poverty. Also, Yoong et al. (2005) reported that consanguineous marriages were $86.4 \%$ among Pakistani children with deafness. While, a positive history of consanguinity was the only significant risk factor $(\mathrm{P}=0.04)$ regarding occurrence of speech disability. Ganga et al. (1991) demonstrated that consanguinity was observed in $65.4 \%$ parents of dumb children, Larsson et al. (2005) showed that there was no statistically significant association between risk of autism and number of antenatal visits. While, a positive history of consanguinity and the mother not receive antenatal care and delivered at home were the significant risk factors $(\mathrm{P}=0.02,0.03$ and 0.01 , respectively) regarding occurrence of motor disability. While, a positive history of consanguinity, the mother not receive antenatal care and delivered at home and the baby not strictly receive vaccination were 
the significant risk factors $(\mathrm{P}=0.01,0.03$, 0.02 and 0.01 , respectively) regarding occurrence of mental disability.

Regarding the stepwise regression analysis of risk factors and general characteristics determined occurrence of disability among the disabled children (table 6), positive consanguinity found to have the highest order (partial $F=2.6$ ) in occurrence of the disabilities among the studied children. Feinmesser et al. (1989); Ganga et al. (1991); Al-Salem and Rawashdeh (1992); Shawky et al. (2002); Abu-Rabia and Maroun (2005); Tabbara et al. (2005) and Yoong et al. (2005) supported our result. Regarding mother not receive antenatal care, we cleared that it has a correlation with occurrence of the disabilities among children (partial $\mathrm{F}=1.9$ ). Shawky et al. (2002) conformed with our result. While, Larsson et al. (2005) did not find a significant relation between risk of autism and antenatal visits. Also, we showed that home delivery have the lowest correlation with occurrence of the disabilities among children (partial $\mathrm{F}=1.6$ ). This result can be accepted and explained, as home delivery carries number of hazards to the mother and her infant, including disability occurrence. On the other hand, baby not strictly receives vaccination found to have a neutral correlation with occurrence of the disabilities among children (partial $\mathrm{F}$ $=1.4$ ).

Regarding distribution of the childhood disabilities in different studied locations according to general characteristics (table 7), $57.6 \%$ and $42.4 \%$ of the disabilities were found among males and females, respectively. Janson and Dawani (1994) found that boys were the majority. MOLISA (1998) reported that prevalence of childhood disability was more among male children. This finding may be the result of both lower risks among females for some specific disabilities and also possible under reporting of disabilities in female children. While, the highest percentages of the disabilities among males and females were found in Al-Giza (72.7\%) and Cairo (52.9\%), respectively. Regarding age,
$17.4 \%, 63.2 \%$ and $19.4 \%$ of the disabilities were found among the age groups $0-6,7-14$ and 15-18, respectively. Chen and Simeonsson (1993) stated that the age specific prevalence rates showed an increase with age. While, the highest percentages of the disabilities in previously mentioned age groups were found in Al-Giza (31.8\%), Alexandria (67.6\%) and Al-Behaira (26.7\%), respectively. As regard cause of the disabilities, $61.8 \%$ and $38.2 \%$ were congenital and acquired, respectively. Costa et al. (1985) supported our result and stated that it is generally believed that $76.0 \%$ of disabilities caused by genetic factors. Andersen et al. (1990) cleared that perinatal damage alone was likely in only three children out of 45, two thirds had a prenatal cause or a combination of prenatal and perinatal causes. Al-Salem and Rawashdeh (1992) reported that genetic causes were responsible for the visual impairment in $77.7 \%$ of subjects in the group born after 1970 and for $67.0 \%$ in the group born before 1970. There was a statistically significant change in the overall pattern (genetic and acquired causes) of blindness between the two generations, and there was also a significant change in the pattern of acquired blindness alone. MOLISA (1998) found that the most prevalent type of childhood disabilities reported was the congenital birth defects $(55.0 \%)$. Nasir et al. (2004) showed that $37.5 \%$ of the disabilities were present at birth. Also, Tabbara et al. (2005) noticed that genetically determined disorders were observed in $70.0 \%$ of children with bilateral blindness and in $56.0 \%$ of children with bilateral visual impairment. The incidence of consanguinity among parents of children with acquired causes was $3.0 \%$ compared to $38.0 \%$ among the genetically determined causes $(\mathrm{P}<0.001)$. On the other hand, Chen and Simeonsson (1993) mentioned that the aetiology of $47.0 \%$ of cases was unknown, $21.0 \%$ of cases resulted from damage prenatally, $3.0 \%$ were due to perinatal factors and $29.0 \%$ were acquired during infancy and early childhood. Woods et al. (2005) cleared that from 3719 discharged hospital patients, 0-20 


\section{E. A. El-Moselhy et al}

years old in Colorado and Utah, adverse events, including disabilities, occurred in about $1.0 \%$ of them. The highest percentages of the congenital and acquired disabilities were found in Cairo $(68.6 \%)$ and Al-Behira (46.7\%), respectively. Regarding course of the disabilities, $80.6 \%$ and $19.4 \%$ of children had stationary and progressive course, respectively. The highest percentages of the stationary and progressive course disabilities were found in Alexandria $(86.5 \%)$ and $\mathrm{Al}-\mathrm{Giza}(27.3 \%)$, respectively. Regarding severity, $4.9 \%$ of children had severe disability. Janson and Dawani (1994) found that $2.6 \%$ of children were classified as moderately or severely affected. Samuel et al. (1995) noticed that $10.0 \%$ had severe disability. Ansari and Akhadar (1998) showed, $0.4 \%$ prevalence of severe impairments. As regard the main source of the habilitation care, $6.9 \%, 9.7 \%, 79.2 \%$ and $4.2 \%$ had community based habilitation, govern-mental habilitation center, private habilitation center and counseled traditional healer, respectively. The highest percentages of the community based habilitation, governmental habilitation center, private habilitation center and counseled traditional healer were found in Cairo (10.0\%), Al-Giza $(36.4 \%)$, Cairo $(90.0 \%)$ and Alexandria (10.8\%), respectively. Lastly, $68.1 \%, 20.8 \%$ and $11.1 \%$ of the disabled children were integrated in a school, kept at home and enrolled in a work, respectively. UNDP (2004) clarified that despite investment and a strong legal commitment by the government, disabled children in Egypt continue to suffer social stigmati-zation and very significant disadvantages, particularly in the area of education. While, the highest percentages of these disabled who integrated in a school, kept at home and enrolled in a work were found in Cairo (74.3\%), Al-Giza $(27.3 \%)$ and Alexandria (18.9\%), respectively.

As regard distribution of different types of disabilities in all studied locations according to general characteristics (table 8), $52.4 \%$ and $47.6 \%$ of visual disability were found among females and males, respectively. MOLISA (1998) reported that prevalence of visual disability was more common among males compared with females, $0.66 \%$ vs. $0.56 \%$, respectively. Khandekar and Abdu-Helmi (2004) stated that the risk of low vision disability was significantly higher in male students than female. As regard hearing disability, 55.6\% and $44.4 \%$ of hearing disabled children were males and females, respectively. Ganga et al. (1991) showed that boys were more often affected, $60.2 \%$. Wake et al. (2004) found that $61.4 \%$ and $38.6 \%$ of their group with hearing loss were males and females, respectively. Also, $73.3 \%$ of the speech disability was found among males. Again, Ganga et al. (1991) cleared that boys were more often affected. Broomfield and Dodd (2004) clarified that the risk of speech disability was higher in males than females. At the same time, mental disability was more found among males, $66.7 \%$. Samuel et al. (1995) found that developmental disorders were more prevalent in boys. Also, $61.9 \%, 66.7 \%, 56.7 \%, 77.8 \%$ and $66.7 \%$ of the visual, hearing, speech, motor and mental disabilities were found in 7-14 years age group, respectively. Khandekar and Abdu-Helmi (2004) reported that the rate of low vision disability was significantly higher among high age group $(\mathrm{p}<0.00001)$. Regarding cause of the disability, $85.7 \%$, $18.5 \%, 40.0 \%, 55.6 \%$ and $86.7 \%$ of the visual, hearing, speech, motor and mental disabilities, respectively were congenital. Andersen et al. (1990) cleared that among the mentally retarded, in more than half, the damage occurred prenatally. Parving (1993) demonstrated that prenatal causes accounted for $55.0 \%$ of hearing disability. Molteno and Lachman (1996) showed that in $45.0 \%$ of cases the disability was prenatal in origin, in $17.0 \%$ perinatal, in $9.0 \%$ postnatal and in a quarter it was idiopathic. As regard severity, there were $2(3.2 \%)$ and 1 (3.7\%) children had severe visual and hearing disabilities, respectively. Andersen et al. (1990) cleared that at age four, $1.4 \%$ and $0.7 \%$ of children had severe visual and auditory defects, respectively. Ancel (2004) found that less than $4.0 \%$ of preterm infants developed severe hearing or visual loss and about 0.5- 
8.6\% developed CP. Smith et al. (2005) cleared that the incidence of acquired and inherited SNHL was common in children living in developing countries, where the prevalence of consanguinity was high. Also, Yoong et al. (2005) reported that congenital infections or dysmorphic features were more common than post-meningitis deafness, $5.0 \%$ and $1.4 \%$, respectively among Pakistani children. Regarding mental disability, $93.3 \%$ of cases were severe. Andersen et al. (1990) found that severe mental retardation was $41.4 \%$. Yaqoob et al. (2004) cleared that in $22.0 \%$ of the cases the onset of mild mental disability was prenatal, $28.0 \%$ of the cases during the postnatal period and in a substantial proportion of the cases $(50.0 \%)$ the cause could not be traced. Also, Yaqoob et al. (2004) showed that the overall prevalence of mild mental disabilities was $6.2 \%$. As regard educational or work opportunities, only $50.0 \%$ of the children with speech disability were integrated in school, although $23.3 \%$ of them were in the school age. Schuler (2004) observed that children with speech disabilities were at risk for reading and writing disabilities. UNDP (2004) cleared that disabled children in Egypt continue to suffer very significant disadvantages, particularly in the area of education.

It could be concluded that childhood disabilities is an important public health problem. Its overall prevalence was $8.8 \%$. The most common prevalent childhood disabilities were visual, speech and hearing. Positive consanguinity and baby not strictly received vaccination were the most important risk factors. While, only positive consanguinity was significantly correlated with all types of the childhood disabilities. Furthermore, positive consanguinity had the highest order of correlation with all types of the childhood disabilities. Identification and appreciation the role of risk factors for childhood disabilities may ultimately lead to improve preventive strategies and decrease burden of the childhood disabilities either physically or psychologically. Also, financial burdens for direct medical cost and lost of productivity will decrease. Certain modifiable maternal risk factors affecting child health still exist in our community, such as consanguineous marriages. Establishment of vaccination programmes for several vaccine-preventable infectious diseases would reduce rates of acquired and permanent disabilities in survivors. Also, childhood disabilities tend to be more common among males, of congenital aetiology and the main source for habilitation was the private centers. It could be recommended that more work should be carried out on a big sample size of population all over Egypt to obtain not only the prevalence of childhood disabilities but also all socioeconomic and health characteristics of disabled children, causes of disability, available services...etc. Also, the need for a strong national childhood disabilities prevention and control strategy and the integration of childhood disabilities preventive and curetive services into the health facilities that women and child use. 
E. A. El-Moselhy et al 
Epidemiological Study Of The Childhood Disabilities........... 
E. A. El-Moselhy et al 
Epidemiological Study Of The Childhood Disabilities........... 
E. A. El-Moselhy et al 


\section{References}

1. Abu-Rabia S and Maroun L (2005): The effect of consanguineous marriage on reading disability in the Arab community. Dyslexia, 11 (1): 1-21.

2. Al-Salem M and Rawashdeh N (1992): Pattern of childhood blindness and partial sight among Jordanians in two generations. J Pediatr Ophthalmol Strabismus, 29 (6): 361-5.

3. Ancel PY (2004): Severe sensorineural impairment in very premature infants: Epidemiological aspects. J Gynecol Obstet Biol Reprod (Paris), 33(6): 461-74.

4. Andersen E, Fledelius HC, Fons $M$ and Haugsted R (1990): An epidemiological study of disability in 4-year-old children from a birth cohort in Frederiksborg County, Denmark. Dan Med Bull, 37 (2): 182-5.

5. Ansari SA and Akhadar F (1998): Prevalence of child disability in Saudi Arabia. Disabil Rehabil, 20(1): 25-8.

6. Broomfield $J$ and Dodd $B$ (2004): Children with speech and language disability: Caseload characteristics. Int $\mathbf{J}$ Lang Commun Disord, 39(3): 303-24.

7. Chen J and Simeonsson RJ (1993): Prevention of childhood disability in the People's Republic of China. Childcare and development, 19: 71-88.

8. Costa T, Scriver CR and Childs B (1985): The effect of Mendelian disease on human health: A measurement. A J Genetics, 7: 231-42.

9. Durkin M (2002): The epidemiology of developmental disabilities in low-income countries. Ment Retard Dev Disabil Res Rev, 8 (3): 206-11.

10. El-Hazmi, MAF (1997): Early recognition and intervention of disability and its complications. East Mediter Health J, 3 (1): 154-61.

11. Feinmesser $M$, Tell $L$ and Levi $H$ (1989): Consanguinity among parents of hearing-impaired children in relation to ethnic groups in the Jewish population of Jerusalem. Audiology, 28 (5): 268-71.

12. Ganga N, Rajagopal B, Rajendran $\mathbf{S}$ and Padmanabhan AS (1991): Deafness in children: An analysis. Indian Pediatr, 28 (3): 273-6.

13. Gelfand S (2004): Assessment of infants and children. In: Essential of audiology
Gelfand S (ed.), Thieme publications, New York-Stuttgart.

14. Gortmaker SL and Sappenfield, W (1984): Chronic childhood disorders: Prevalence and impact. Ped Clin N A, 31:3-18.

15. Hutchison $\mathbf{T}$ and Gordon $D$ (2005): Ascertaining the prevalence of childhood disability. Child Care Health Dev, 31 (1): 99-107.

16. Janson S and Dawani H (1994): Chronic illness in preschool Jordanian children. Ann Trop Paediatr, 14 (2): 137-44.

17. Khandekar RB and Abdu-Helmi $\mathbf{S}$ (2004): Magnitude and determinants of refractive error in Omani school children. Saudi Med J, 25 (10): 1388-93.

18. Larsson HJ, Eaton WW, Madsen KM, Vestergaard M, Olesen AV, Agerbo E, Schendel D, Thorsen $P$ and Mortensen PB (2005): Risk factors for autism: Perinatal factors, parental psychiatric history and socioeconomic status. AJ Epidemiol, 161 (10): 916-25.

19. Marlow N, Wolke D, Bracewell MA, Samara $M$ and EPI Cure Study Group (2005): Neurologic and developmental disability at six years of age after extremely preterm birth. N Engl J Med, 352 (1): 9-19.

20. MOLISA (Ministry of Labour, Invalids and Social Affairs) (1998): Vietnam child disability survey 1998. Centere for information and statistics on labour and social affairs.

21. Molteno C and Lachman P (1996): The aetiology of learning disability in preschool children with special reference to preventability. Ann Trop Paediatr, 16 (2): 141-8.

22. Nasir JA, Chanmugham P, Tahir F, Ahmed A and Shinwari F (2004): Investigation of the probable causes of specific childhood disabilities in eastern Afghanistan (preliminary report). Cent Eur J Public Health. 12 (1): 53-7.

23. Parving A (1993): Hearing disability in childhood: A cross-sectional and longitudinal investigation of causative factors. Int J Pediatr Otorhinolaryngol, 27(2): 101-11.

24. Roubertie A, Leyd J, Rivier F, Humbert C, Laude V, Cheminal $R$ and Echenne B (2004): Movement disorders in 


\section{E. A. El-Moselhy et al}

childhood: therapeutic update. Arch Pediatr, 11(8): 951-4.

25. Samuel E, Lerman-Sagie T, Nevo $Y$ and Harel S (1995): Epidemiology of developmental disorders in children in Tel Aviv. Harefuah, 128 (12): 759-62.

26. Schuele CM (2004): The impact of developmental speech and language impairments on the acquisition of literacy skills. Ment Retard Dev Disabil Res Rev, 10 (3): 176-83.

27. Shawky S, Abalkhail B and Soliman N (2002): An epidemiological study of childhood disability in Jeddah, Saudi Arabia. Paediatr Perinat Epidemiol, 16 (1): 61-6.

28. Smith RJ, Bale JF Jr, White KR (2005): Sensorineural hearing loss in children. Lancet, 365 (9462): 879-90.

29. Tabbara FK, El-Sheikh HF and Shawaf SS (2005): Pattern of childhood blindness at a referral center in Saudi Arabia. Ann Saudi Med, 25 (1): 18-21.

30. UNDP (United Nations Development Programme) (2004): United Nations Development Programme. Egypt Human Development Report.
31. Wake M, Hughes E, Collins CM and oulakis $Z$ (2004): Parent-reported ealthrelated quality of life in children with congenital hearing loss: A population study. Ambul Pediatr, 4 (5): 411-7.

32. WHO (1980): International classification of impairment, disability and handicaps. WHO Publications, Geneva.

33. WHO (2004): Disability and Health. WHO Publications, Geneva.

34. Woods D, Thomas E, Holl J, Altman S and Brennan $T$ (2005): Adverse events and preventable adverse events in children. Pediatrics, 115(1): 155-60.

35. Yaqoob M, Bashir A, Zaman $\mathbf{S}$, Ferngren $H$, Von Dobeln $U$ and Gustavson KH (2004): Mild intellectual disability in children in Lahore, Pakistan: Aetiology and risk factors. J Intellect Disabil Res, 48 (7): 663-71.

36. Yoong SY, Feltbower R, Spencer $\mathbf{N}$ and McKinney PA (2005): Families affected by deafness: hospital services uptake in a multiethnic population. Arch Dis Child, 90 (5): 454-9. 


\section{دراسة وبائيه للإعاقات فى مرحله الطقولة: مسح منزلى في أربع محافظات مصرية}

عصام عبد المنعم المصيلحي-رائد محمد العزب_ حامد عمر خليفةـ إيمان شكرى عبد

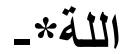

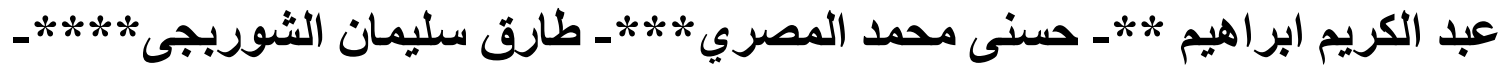

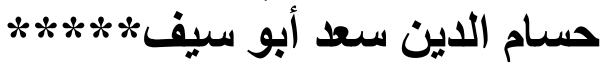

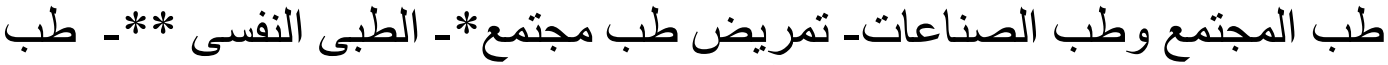

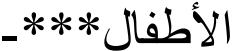

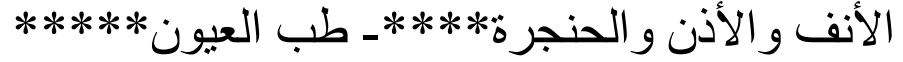

أجريت هذه الدراسة على 1403 طفل في أربع محافظات مصرية هي الاسكندرية

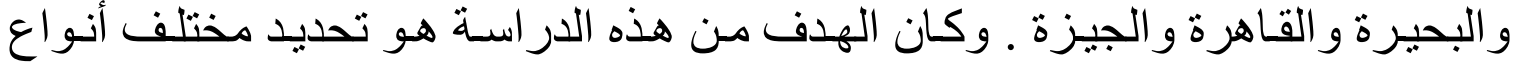

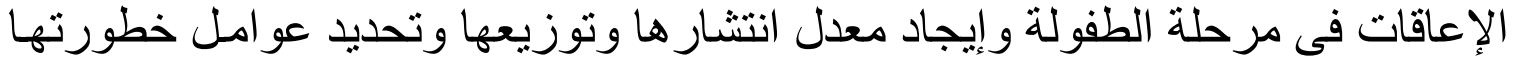

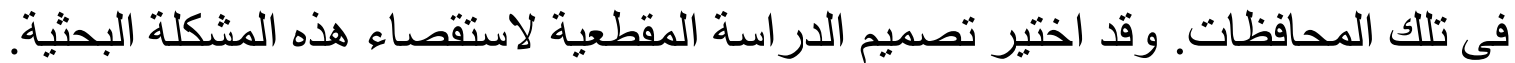

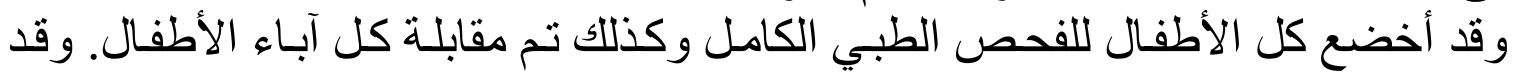

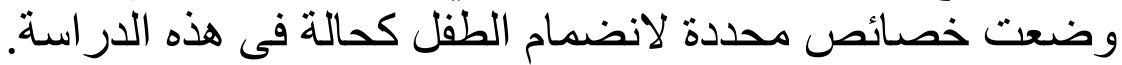

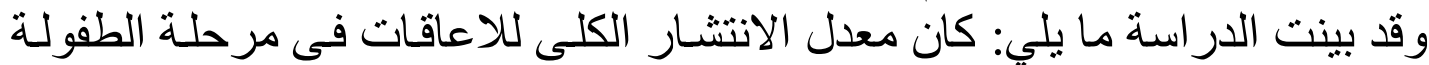

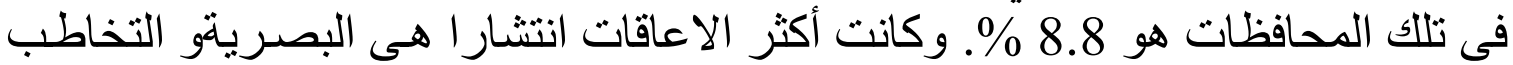

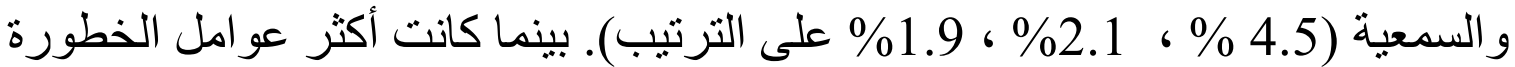

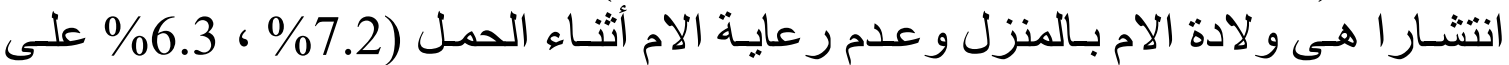

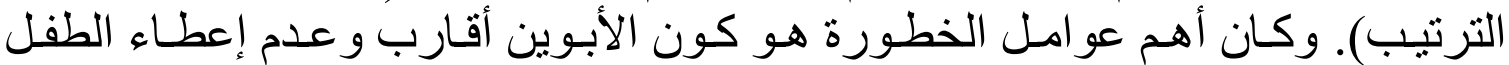

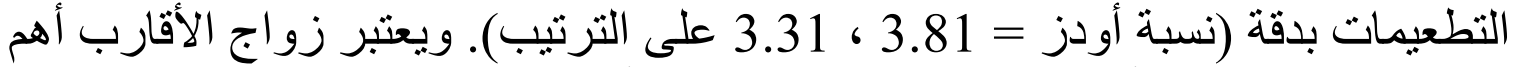

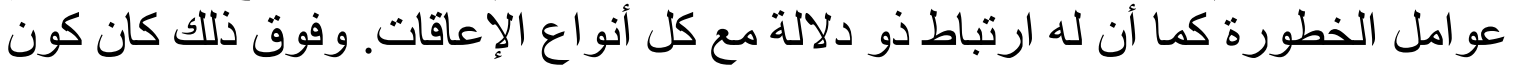

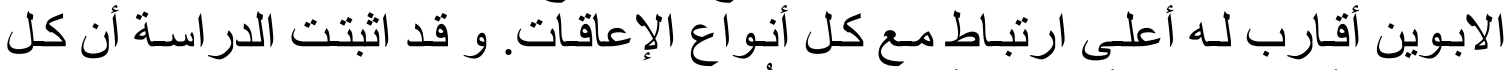

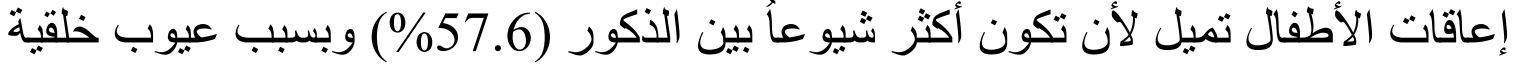
(61.8 \%) كماوجد أن المصدر الرئيسى للتاهيل هو مر اكز التأهيل الخاصـة ( 79.2 